\title{
Interactions between Phospholipid Monolayers (DPPC and DMPC) and Anesthetic Isoflurane Observed by Quartz Crystal Oscillator
}

\author{
Yasushi Yamamoto1* ${ }^{*}$ Takashi Yokoyama ${ }^{1}$, Daisuke Yoshida1, Hiroya Mori', \\ Karina Sekiguchi1, Takatsugu Shimoaki', Akihiro Yoshino1, Keijiro Taga1, \\ Zameer Shervani ${ }^{2,3}{ }^{*}$, Masato Yamamoto ${ }^{4}$ \\ ${ }^{1}$ Department of Materials Science and Engineering, Nagoya Institute of Technology, Nagoya, Japan \\ ${ }^{2}$ Tohoku Foods Corporation Limited, Sendai, Japan \\ ${ }^{3}$ Department of Chemistry, Graduate School of Science, Tohoku University, Sendai, Japan \\ ${ }^{4}$ College of Arts and Sciences, Showa University, Fujiyoshida, Japan \\ Email: yamamoto.yasushi@nitech.ac.jp
}

Received 17 February 2015; accepted 27 March 2015; published 31 March 2015

Copyright (C) 2015 by authors and Scientific Research Publishing Inc.

This work is licensed under the Creative Commons Attribution International License (CC BY). http://creativecommons.org/licenses/by/4.0/

(c) () Open Access

\section{Abstract}

The interactions of phospholipid monolayers (dipalmitoyl phosphatidyl choline; DPPC and dimyristoyl phosphatidyl choline; DMPC) with volatile anesthetic isoflurane were investigated using quartz crystal microbalance (QCM) and quartz crystal impedance (QCI) methods. The quartz crystal oscillator was attached horizontally on the surface of DPPC and DMPC monolayer formed on the water surface. Physisorption of isoflurane hydrate at the DPPC monolayer surface was monitored in terms of frequency and resistance change of quartz crystal on addition of anesthetics isoflurane. Both frequency and resistance change showed the elastic nature of DPPC monolayer. Measurement of DMPC monolayer-isoflurane hydrate revealed the expandable nature of DMPC monolayer. Variation of frequency and impedance of DPPC and DMPC monolayer on addition of isoflurane which proved a two-step change has occurred at monolayer surface at isoflurane concentration of $\leq 8 \mathrm{mM}$ that has been attributed to isoflurane aggregation at monolayer/water interface. Isoflurane hydrates formed in the process have capability to affect the interfacial properties of monolayer such as existence of structured water.

\section{Keywords}

Physisorption, DPPC Monolayer, DMPC Monolayer, Quartz Crystal Oscillator, Anesthetic

\footnotetext{
${ }^{*}$ Corresponding authors.
}

How to cite this paper: Yamamoto, Y., et al. (2015) Interactions between Phospholipid Monolayers (DPPC and DMPC) and Anesthetic Isoflurane Observed by Quartz Crystal Oscillator. Journal of Biophysical Chemistry, 6, 42-53. 


\section{Isoflurane-Monolayer Interaction}

\section{Introduction}

Biomembranes have fluidic structures where proteins are buried in lipid bilayers. Lipids are composed of various kinds of phospholipids; a few of them are glycerol- and sphingophospholipids. Each protein and lipid has different functions for that they are called functional proteins and lipids. Investigation of function and structure reveals that intermolecular interactions such as: hydrogen bonding, hydrophobic, van der Waals interactions have an important role in performance of these biomolecules. Researchers [1]-[4] had been actively investigating membrane rigidity, flexibility, dynamics, aggregation and dispersion. The action of anesthesia also is related to the above physical properties of membranes. Effectiveness and action of anesthetic agent on living organism are related to the above properties of membranes. Anesthesia agent molecules interact with lipid biomembrane [5]-[9] of the organism to inhibit sensory perception of whole of the body or part of the body of living organism. Volatile anesthesia molecule work exhibits anesthetic effect at high concentration in the order of mM in body fluid that is different from general medicine which is much more effective at lower concentration as low as nM. Investigations [10] [12] show anesthetic strength or anesthetic potency is temperature dependent. Various studies [8] [9] [13]-[15] conducted based on experimental and clinical facts reach to the conclusion that anesthesia phenomena is physisorption where anesthetic aggregation acts indirectly on biomembrane-body fluid interface. Among various physicochemical techniques, quartz crystal oscillator (QCO) method is a powerful tool to investigate the interactional phenomena in liquid phases. QCO method is mainly divided into quartz crystal microbalance (QCM) and quartz crystal impedance (QCI) equipment. QCM can detect a mass change in the range nanogram order [16] [17] and is used in the analysis of adsorption phenomena such as oxidation and reduction processes occurring on a self-assembled monolayer [18], metal ion binding to the Langmuir monolayer [19], and molecular recognition of DNA strands and lipids [20]-[22]. QCI can also detect the viscosity or elasticity of adsorbed layers on the QCO independent of mass adsorption that has been applied to investigate the properties of adsorption or immobilization on liquid surfaces and also has been applied in hybridization of DNA [23], phase transition of adsorbed Langmuir-Blodgett (LB) film [24], and precipitation denaturation of proteins [25] [26].

In this study, we have investigated physisorption interactions between phospholipid monolayers (dipalmitoyl phosphatidyl choline, DPPC; dimyristoyl phosphatidyl choline, DMPC) as the model membrane and anesthetic isoflurane using our home designed and assembled high sensitive QCO apparatus [15] [27]-[29], where the QCO was attached horizontally on those monolayers formed on the water surface. DPPC and DMPC are one of main components on the membrane and have the following characteristics on the point of "molecule"; these have a common hydrophilic phosphatidyl choline group, while the length of two alkyl chains is different (DPPC is longer than DMPC). On the measured temperature in this study $\left(26^{\circ} \mathrm{C}\right)$, DPPC forms gel state and DMPC liquid-crystal state [29]. We have discussed the behavior of interfacial layer (monolayer and interfacial structured water) with the action of anesthetic, and the relation to the anesthesia phenomenon from the viewpoint of change in interfacial properties [8] [9] [14] [15].

\section{Experimental}

\subsection{Materials}

DPPC (>99\%) and DMPC (>99\%) which were used as the model membrane lipids were purchased from Avanti polar lipids (AVT) Inc. and used without further purification. Volatile anesthetic isoflurane which has chemical formula, 1-Chloro-2,2,2-trifluoroethyl difluoromethyl ether, was purchased from Abbott Japan Corp. Ltd. The concentrations of isoflurane in aqueous solution were in the range of 1 - $8 \mathrm{mM}$. Spreading solvent for DPPC and DMPC monolayers was chloroform (99.0\%, Wako Pure Chemical Industries Ltd.). Purified water (conductance $<0.07 \mu \mathrm{S} / \mathrm{cm}$ ) for subphase was obtained using a Super Water Purifying System (WL-21P; Yamato Scientific Corp. Ltd.), and further boiled for $10 \mathrm{~min}$ and subsequently cooled to room temperature before use.

\subsection{Methods and Apparatus}

On the formation of each DPPC and DMPC monolayer, we adopted the dropping method at which solution 
droplets containing monolayer sample are dropped continuously on the water surface [30]. About $1 \mathrm{mM}$ solution of each DPPC and DMPC in chloroform was spread on the water surface using a $100 \mu \mathrm{l}$ microsyringe (Ge-0583 - 04; Hamilton Co., Nevada, USA). The spreading was conducted at $0.5 \mu \mathrm{l} / 30$ s intervals. The process of monolayer formation was checked by the surface pressure versus area isotherm curves using the Wilhelmy method (Surface Tensiometer, CBVP-A3; Kyowa Interface Science Co., Ltd., Saitama, Japan) and Langmuir type selfassembled monolayers were formed spontaneously on the water surface [15] [27] [28] [30].

Details of the experimental apparatus used for QCM and QCI measurements have been reported previously [15] [27] [28]. A brief description is given as following. QCO with a frequency of $6 \mathrm{MHz}$ was purchased from Hokuto Denko Corp. (Tokyo, Japan) and the area of the Au electrode was $133 \mathrm{~mm}^{2}$. The QCO which was fixed with an O-ring in a poly(tetrafluoroethylene) holder was moved carefully $(10 \mathrm{~mm} / \mathrm{s})$ using a micrometer and attached horizontally to the monolayer formed on the water surface. Each DPPC and DMPC monolayer was physically attached to the electrode surface of the QCO by the hydrophobic interaction between hydrophobic Au electrode surface and hydrophobic group (alkyl chain) of the monolayer [31]-[33]. Anesthetic isoflurane was added from the bottom of measurement trough through the tube fixed to the trough. Using a magnetic stirrer, the stirring bar was stirred slowly $(1 \mathrm{r} / \mathrm{s})$ and isoflurane was dissolved into the water subphase. Thus, stirring did not affect the monolayer stability because of slow stirring. The temperature during the measurement was maintained at $26.00^{\circ} \mathrm{C} \pm 0.01^{\circ} \mathrm{C}$ using a double water bath.

For the QCM measurement, the frequency $F$ of the QCO was measured by a Universal Counter (TR5822; Advantest Corp., Tokyo, Japan) and conducted at 1 min intervals. After the stabilization of $F$ contacting the monolayer to within $\pm 0.5 \mathrm{~Hz}$, isoflurane was injected slowly at the rate $1 \mathrm{ml} / \mathrm{s}$ using a $100 \mu \mathrm{l}$ microsyringe. The change in $F$ was observed before and after the addition of isoflurane. For the QCI measurement, the resistance $R$ in the QCO circuit was measured by an impedance-gain phase analyzer (SI1260; Solartron Analytical, Hampshire, UK) and conducted at 10 min intervals. $R$ corresponds to the viscosity change at the QCO interface, and from the viewpoint of membrane fluidity we specially addressed the analysis of $R$ [34] [35]. After the stabilization of $R$ of QCO contacting the monolayer to within $\pm 0.02 \Omega$, isoflurane was injected slowly; this process was identical to that used for the QCM measurement. The change in $R$ of QCO was observed before and after the addition of isoflurane. Each QCM and QCI measurement was conducted more than two times to maintain the reproducibility of the data. The experimental errors were noticed within $\pm 0.5 \mathrm{~Hz}$ for QCM and $\pm 0.05 \Omega$ for QCI.

\section{Results}

\subsection{Time Course of Frequency (QCM) and Resistance (QCI)}

Figure 1 shows a typical time course of frequency (QCM) and resistance (QCI) for QCO in contact with a DPPC monolayer after adding isoflurane of $5 \mathrm{mM}$ concentration (bulk phase) at $26^{\circ} \mathrm{C}$. Figure 1 also shows the pattern of QCM and QCI changes observed by the addition of isoflurane. Lower half of figure represents change in frequency $\Delta F(\mathrm{~Hz})$ and upper half is resistance change $\Delta R(\Omega)$ after addition of anesthetic isoflurane. After stable base line was reached for both the experiment, isoflurane was added in the water subphase at the time shown by horizontal marker A. After the addition of isoflurane, $\Delta F$ decreased gradually due to increase in adsorption while $\Delta R$ showed an increase due to increase in viscosity responding to isoflurane addition. Both $\Delta F$ and $\Delta R$ approached an equilibrium state after three and half hour of isoflurane addition. Isoflurane being hydrophobic in nature possesses little solubility in water and it is stirred slowly in the water subphase at the rate $1 \mathrm{r} / \mathrm{second}$, therefore, the delayed response (ca. $1 \mathrm{~h}$ ) after the addition probably corresponds to the necessary time for the dissolution of isoflurane into the water subphase and the diffusion of isoflurane from bulk solution (water subphase) toward the DPPC monolayer/water interface. Authors [15] [27] [28] [36] also reported such kind of delay in equilibrium with similar systems. Since the viscosity change in the DPPC monolayer occurs by the adsorption of isoflurane, the starting time of change in $\Delta R$ is a little later than that in $\Delta F$. On both $\Delta F$ and $\Delta R$, few hours are needed to approach the equilibrium state. In general adsorption phenomenon as measured by QCO for monolayer, the addition reaction to the specific part of monolayer (chemisorption) is often occurred faster and the reaction time finishes in minutes contrary to physisorption that took hours to reach equilibrium [20]-[22] [31] [32]. A specific part in which isoflurane is likely to combine is not found in DPPC molecule, therefore, the present research is observing the physisorption phenomenon of the interaction between the DPPC monolayer and isoflurane. The long time until reaching an equilibrium state also indicates that it is physisorption phenomenon.

In the case that the change in each $\Delta F$ and $\Delta R$ is observed, we decided to define the difference of the value 


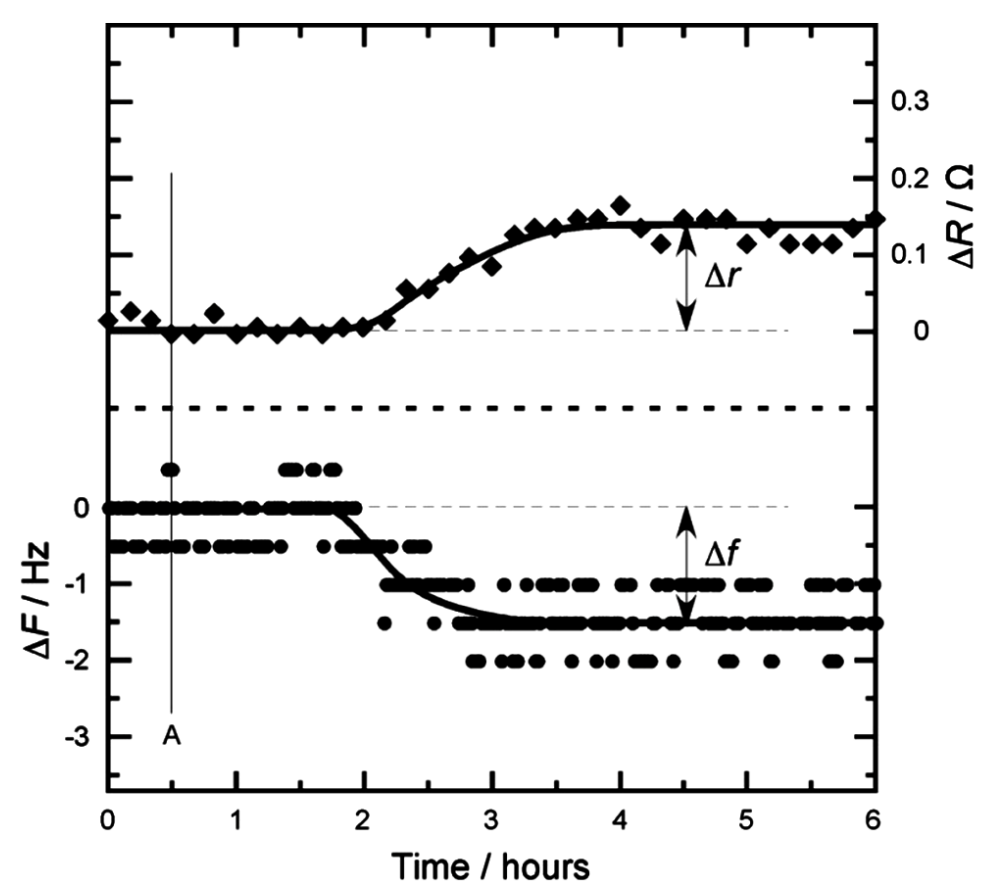

Figure 1. Typical time course of $\Delta F(\mathrm{QCM})$ and $\Delta R(\mathrm{QCI})$ of $\mathrm{QCO}$ in contact with DPPC monolayer after adding anesthetic isoflurane of $5 \mathrm{mM}$ concentration (bulk phase) at $26^{\circ} \mathrm{C}$. Lower: $\Delta F$, Upper: $\Delta R$. Isoflurane was added in the water subphase at the time of line A. Inserted $\Delta f$ and $\Delta r$ show each amount of change in frequency and resistance.

before and after the addition of isoflurane as respective $\Delta f$ for QCM and $\Delta r$ for QCI (inserted in Figure 1). In the following section, we have described and discuss the concentration dependence of isoflurane action to each DPPC and DMPC monolayer using $\Delta f$ and $\Delta r$.

\subsection{Concentration Dependence of $\Delta f(\mathrm{QCM})$ and $\Delta r(\mathrm{QCI})$}

\subsubsection{DPPC versus Isoflurane}

Figure 2 shows the isoflurane concentration dependent behavior of frequency $\Delta f(\mathrm{QCM})$ (a) and resistance $\Delta r$ (QCI) (b) as measured by QCO in contact with a DPPC monolayer at $26^{\circ} \mathrm{C}$. The horizontal axis represents the isoflurane concentration in bulk phase and vertical axis represents frequency change ( $\Delta f$ ) in Figure 2(a) and resistance change ( $\Delta r$ ) in Figure 2(b). From Figure 2(a) it is clear that there was no change in $\Delta f$ at concentration $<2 \mathrm{mM}$. At concentration $>2 \mathrm{mM}, \Delta f$ gradually increased with increase in isoflurane concentration and approached asymptotically to a saturation value of $1.6 \mathrm{~Hz}$ at around $6 \mathrm{mM}$ of isoflurane concentration. After $6 \mathrm{mM}$ addition, a second stage sharp increase in $\Delta f$ was observed reaching a second saturation value of $3.1 \mathrm{~Hz}$. This pattern of a two-step increase is similar to Langmuir or BET (Brunauer, Emmett and Teller) adsorption isotherm. On QCI measurement (Figure 2(b)) there was no increase in $\Delta r$ until $4 \mathrm{mM}$ concentration of isoflurane. At concentration $>4 \mathrm{mM}, \Delta r$ showed increase in value and reached asymptotically to $0.14 \Omega$ at around $6 \mathrm{mM}$. At concentration $>6 \mathrm{mM}$ there is a slight increase in $\Delta r$ value and then change in resistance remaining constant. The pattern of adsorption isotherm DPPC monolayer-isoflurane is similar to that of DPPC-enflurane isotherm [15] and DHP-halothane interaction [28]. These observations suggest that DPPC monolayer-isoflurane interactions are specific compared to the general adsorption process as studied by other authors [20]-[22] [31] [32].

\subsubsection{DMPC versus Isoflurane}

Figure 3 shows the isoflurane concentration dependent behavior of frequency $\Delta f(\mathrm{QCM})$ in Figure 3(a) and resistance $\Delta r(\mathrm{QCI})$ in Figure 3(b) for QCO in contact with a DMPC monolayer at $26^{\circ} \mathrm{C}$. On the QCM measurement, $\Delta f$ gradually increased with an increase in isoflurane concentration and approached asymptotically to a saturation value of $2.2 \mathrm{~Hz}$ at around $5 \mathrm{mM}$ of isoflurane concentration. A further increase in concentration 


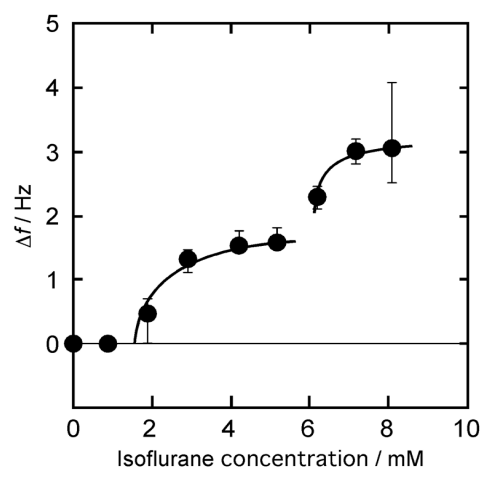

(a)

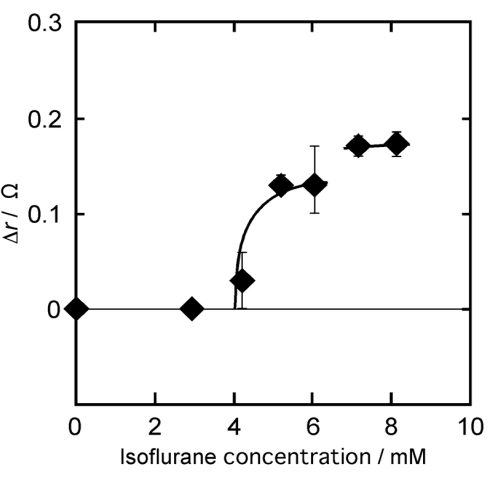

(b)

Figure 2. Isoflurane concentration dependent behavior of $\Delta f$ (a) and $\Delta r$ (b) for QCO in contact with DPPC monolayer at $26^{\circ} \mathrm{C}$. Changes in $\Delta f$ and $\Delta r$ are defined in Figure 1 . Increase in $\Delta f$ shows the decrease in actual value $F$. The curve of first step in $\Delta f$ is fitted by referred to Langmuir adsorption isotherm.

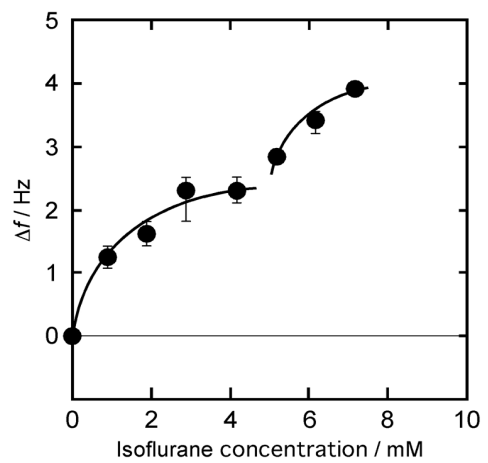

(a)

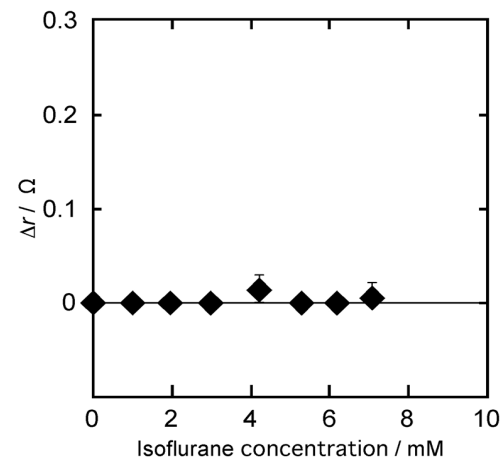

(b)

\begin{abstract}
Figure 3. Isoflurane concentration dependent behavior of $\Delta f$ (a) and $\Delta r$ (b) for QCO in contact with DMPC monolayer at $26^{\circ} \mathrm{C}$. Changes in $\Delta f$ and $\Delta r$ are defined in Figure 1. Increase in $\Delta f$ shows the decrease in actual value $F$. The curve of first step in $\Delta f$ is fitted by referred to Langmuir adsorption isotherm.
\end{abstract}

showed a second stage increase. At isoflurane $8 \mathrm{mM}$ second saturation value of $\Delta f$ reached to $3.8 \mathrm{~Hz}$. These processes are similar to the Langmuir's or BET's adsorption isotherm and have similarity to isoflurane-DPPC monolayer isotherm as described above in this work. While on the QCI (Figure 2(b)), there was no change in $\Delta r$ at the measured concentration range 1 to $10 \mathrm{mM}$ of isoflurane introduction to DMPC monolayer. This result is different from that of DPPC monolayer where $\Delta r$ changed by the addition of isoflurane hydrate to the DPPC monolayer-water interface (Figure 2(b)). This suggests that physisorption is different in terms of membrane resistance of isoflurane with DPPC and DMPC monolayers.

\title{
4. Discussion
}

\section{1. $\pi$ - $A$ Isotherm Curves of DPPC and DMPC Monolayers}

Figure 4(a) shows the surface pressure versus molecular area $(\pi-A)$ isotherm curve of DPPC monolayer at $26^{\circ} \mathrm{C}$ as measured by dropping method (solid marks $(\boldsymbol{\Delta})$ ). Horizontal axis represents molecular area calculated from molecular numbers in dropping volume and vertical axis is surface pressure recorded when equilibrium is reached to a constant pressure after some time of dropping DPPC/chloroform droplet. Figure 4(a) also shows a typical $\pi$ - $A$ isotherm curve using the compression method taken from references (solid line (-)) [37] [38].

Many isotherm studies for DPPC monolayer by the compression method have shown that the DPPC 


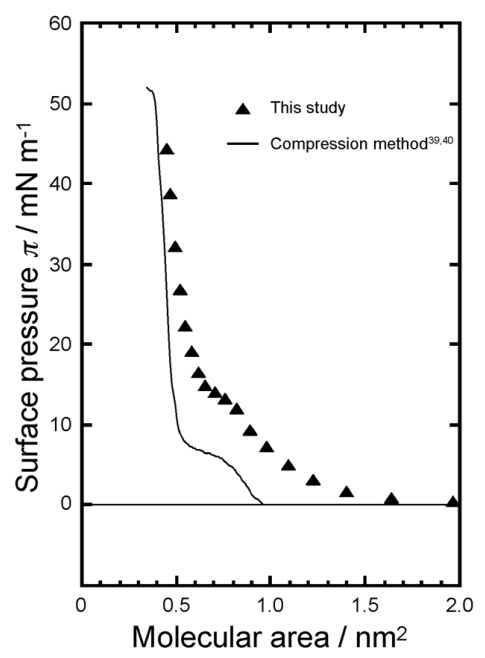

(a)

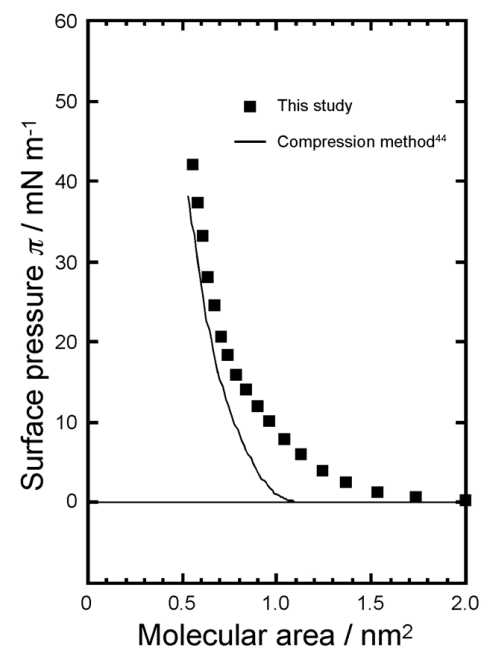

(b)

Figure 4. Surface pressure versus molecular area $(\pi-A)$ isotherm curves of DPPC monolayer (a) and DMPC monolayer (b) at $26^{\circ} \mathrm{C}$. Solid marks $(\boldsymbol{\Delta}, \boldsymbol{\nabla})$ : dropping method for DPPC monolayer $(\boldsymbol{\Delta})$ and DMPC monolayer ( $\mathbf{\square})$. Solid line (-): compression method for both monolayers.

monolayer forms the following three types of molecular arrangements: liquid-expand (LE) state at low surface pressure, liquid-condensed (LC) state at higher surface pressure, and LE-LC transition state also known as plateau range at a surface pressure of approximately $8 \mathrm{mN} / \mathrm{m}$. After LE-LC transition the pressure increased steeply up to $50 \mathrm{mN} / \mathrm{m}$ (solid line). The limiting molecular area $\left(A_{0}\right)$ is $c a .0 .50 \mathrm{~nm}^{2} /$ molecule [39].

The isotherm curve constructed by the dropping method in our measurement had a different shape compared to compression method. Surface pressure increased gradually at molecular area $1.7 \mathrm{~nm}^{2}$ where in compression method increase was at $1.0 \mathrm{~nm}^{2}$. After LE-LC transition state finishes at $12 \mathrm{mN} / \mathrm{m}$, surface pressure surface pressure steeply increased up to $42 \mathrm{mN} / \mathrm{m}$. $A_{0}=0.65 \pm 0.05 \mathrm{~nm}^{2}$ and $30 \%$ larger than recorded by compression method.

In DPPC monolayer, two alkyl chains are all-trans type and also in rotational degree of freedom in each chain axis [29]. The cross sections area of chains is smaller than that of hydrophilic group. Larger $A_{0}$ indicates that the hydrophilic group of DPPC molecules and water molecules would structure better and maintain themselves in the most comfortable hydrogen-bonding network via hydrophilic interaction at the DPPC monolayer-water interface thus there exists interfacial structured water [40]. DPPC monolayer formed in our experiment by the dropping method is semi-expanded state and has a flexible and elasticity, and fluidic structure. Hydrophilic interaction would control the formation of DPPC monolayer stronger than hydrophobic interaction between cylinder like alkyl chains. In addition, the present $\pi-A$ isotherm was similar to those reported previously [15] [27] [30] [41].

Figure 4(b) shows the surface pressure versus molecular area $(\pi-A)$ isotherm curve of DMPC monolayer at $26^{\circ} \mathrm{C}$ using the dropping method (solid marks (-)). A horizontal axis represents molecular area and a vertical axis surface pressure. Figure 4(b) also shows a typical $\pi$-A isotherm curve using the compression method (solid line (-)) [42].

Many isotherm studies for DMPC monolayer by the compression method have shown that DMPC monolayer forms only one LE state. Surface pressure increases gradually from about $1.1 \mathrm{~nm}^{2}$ of molecular area and pressure increased monotonously up to $36 \mathrm{mN} / \mathrm{m}$. The limiting molecular area $A_{0}$ is $0.78 \mathrm{~nm}^{2} /$ molecule [39].

The isotherm curve constructed by the dropping method in our experiment also presented a typical LE state. Surface pressure increases gradually at $1.4 \mathrm{~nm}^{2}$ molecular area and kept monotonously increased up to $41 \mathrm{mN} / \mathrm{m}$. $A_{0}$ was $0.80 \pm 0.05 \mathrm{~nm}^{2} /$ molecule and the measured value was quite similar to that recorded by other authors by compression method.

In the case of DMPC, two alkyl chains are disordered partially at $26^{\circ} \mathrm{C}$ and the structure has gauche type conformation [40]. Cross section area of chain is larger than that of hydrophilic group. Actually, $A_{0}$ of DMPC mo- 
nolayer is certainly larger than that of DPPC monolayer; nevertheless both DMPC and DPPC have the same hydrophilic group phosphatidyl choline functionality. The DMPC monolayer by the dropping method is expanding state and maintains its expandability [43]. Hydrophobic interaction between partially disordered alkyl chains would control the formation of DMPC monolayer stronger than hydrophilic interaction between hydrophilic group of DMPC molecules and water molecules. This implies that the DMPC monolayer is not dependent on the monolayer formation method, different from the DPPC monolayer. Because of large surface area of alkyl chain of DMPC compared to DPPC, hydrogen bonding between polar part of DMPC and water i.e. interfacial structured water is not stable as in DPPC.

\subsection{Isoflurane}

Isoflurane has chemical formula $\mathrm{CF}_{2} \mathrm{H}-\mathrm{O}-\mathrm{CClH}-\mathrm{CF}_{3}$ and a typical inhalation anesthetic. It was synthesized by Terrell group in 1965. Clinical use was permitted at the USA in 1980. Since then anesthesia application has been spread widely [5]-[7]. Isoflurane is a halogenated ether structure anesthetic and it is based on the structure and properties of early period used anesthetics such as diethyl ether and chloroform. Isoflurane is a semi hydrophobic molecule containing oxygen, fluorine, and chlorine atoms, and possesses the solubility $10 \mathrm{mM}$ at $26^{\circ} \mathrm{C}$ [44] [45]. Isoflurane when dissolved in aqueous solution, water molecules surround the isoflurane and form isoflurane hydrates [44] [46].

\subsection{Interaction between Monolayers and Isoflurane}

${ }^{1}$ H-NMR spectroscopy has showed that anesthetics (halothane, enflurane, methoxyflurane, and chloroform) show different actions on the isothermal phase transition between the lipid core and the hydrophilic interface in a DPPC vesicle [47]. DSC and X-ray scattering investigation have also showed that enflurane preferentially interacts with DPPC lamellar-phase-water and DPPC liposomes-water interface and causes the structural change of each lamellar phase and liposomes [48]. ${ }^{1} \mathrm{H}$ - and ${ }^{19} \mathrm{~F}-\mathrm{NMR}$ spectroscopy have been proved that halothane and enflurane interact with the sodium dodecyl sulfate (SDS) micelle-water interface and the molecular axis of the halothane is perpendicular to the interface, while that of enflurane is parallel [49] [50]. ${ }^{2} \mathrm{H}$ NMR spectroscopy has showed that the interfacial structured water in the glycerol $a$-monooleate (GMO) emulsion-water interface changes into free water by enflurane hydrates [51]. These reports that anesthetic hydrates interact with and release the interfacial structured water formed on the membrane-water interface without penetrating into the membrane lipid core, in other words, anesthetic hydrates physisorb on the interface and have a possibility of changing the properties of interface including membrane.

Based on the above-published reports the interactions between isoflurane and DPPC or DMPC have been explained as followings.

\subsubsection{The Interaction between DPPC Monolayer and Isoflurane}

The present DPPC monolayer is an elasticity rich monolayer as mentioned in Section 4.1. There is possibility that the structural change in monolayer-water interface occurred by the physisorption of isoflurane hydrate. As described in Figure 2(a), in first saturation range $2-6 \mathrm{mM}$, isoflurane hydrates physisorb on the interfacial structured water formed on the DPPC monolayer-water interface leading increase in $\Delta f$ which has direct relation with mass increase due to isoflurane hydrate adsorption. Small amount of isoflurane hydrate $(\leq 3 \mathrm{mM})$, has not effected $\Delta r$ i.e. viscosityof the membrane. Interfacial viscosity of DPPC monolayer-structured water increased when at isoflurane hydrate concentration $\geq 4 \mathrm{mM}$. Further increase in the amount of physisorbed isoflurane hydrate (increases in $\Delta f$ ) would influence the structured water because of the occurrence of the interaction between physisorbed isoflurane hydrates and the structured water. As a result, "distortion" and "release" of the structured water occur and the interfacial structured water including isoflurane molecules is reconstructed at the interface [51]. Those processes promote the interaction between released hydrophilic groups of DPPC molecules and also decrease in the distance between those groups. Moreover, the interfacial structure may be strengthened by the existence of isoflurane molecule, because semi-hydrophobic isoflurane interacts more strongly with hydrophilic groups of DPPC molecules instead of structured water molecules. Those synergistic effects would show up as an increase in $\Delta r$ (increase in viscosity) on the interface. This implies that the fluctuation of the fluid-structured DPPC monolayer is suppressed i.e. partial increase in the density of the DPPC monolayer.

From reaching to first saturation values of both $\Delta f(1.6 \mathrm{~Hz})$ and $\Delta r(0.14 \Omega)$ at around $6 \mathrm{mM}$ (Figure 2), we 
roughly estimated the mean molecular area of isoflurane hydrate from the value of $\Delta f\left(1.6 \mathrm{~Hz}=19.5 \mathrm{ng} / \mathrm{cm}^{2}\right.$ (Sauerbrey's equation)) as worked out by QCM [15] [28] [36] [41]. Here, we neglected the effect of the interfacial viscosity change $(\Delta r)$. Yoshino et al. have reported that the amount of hydrated water surrounding one enflurane molecule is 30 [51]. Isoflurane is a structural isomer of enflurane, thus we assumed 30 of hydrated water molecules for isoflurane. The molecular area of the isoflurane hydrate was calculated as $6.2 \mathrm{~nm}^{2} /$ one-hydrate. It is also assumed that isoflurane hydrate is "elliptical shape" of which the molecular axis of hydrate is calculated the major one, the apparent molecular areas along the major and the minor axes were $1.5 \mathrm{~nm}^{2} /$ one-hydrate and $1.3 \mathrm{~nm}^{2} /$ one-hydrate, respectively [52]. Considering these sizes of isoflurane hydrate, physisorption layer of isoflurane hydrates would be formed on the interface, where isoflurane molecules are not in a dense state and maintain a semi-saturation state.

On the higher concentration at more than $6 \mathrm{mM}$ (Figure 2), isoflurane hydrates would physisorb still more on the interface, because the interface is already occupied at the semi-saturation level by the physisorbed isoflurane hydrates and also loses its function as a barrier to the next physisorbed hydrates. Therefore, the following two possibilities either multi-physisorption of isoflurane hydrates or promotion of aggregation between hydrates would occur at the interface [13] [15] [27] [28]. At multi-physisorption model, continuous physisorption of isoflurane hydrates and increase in $\Delta f$ leads to the formation of isoflurane hydrate multilayer. The multilayering is also suppressing more strongly the interface including DPPC monolayer. This effect would cause a discontinuous and subsequent a slight increase in the interfacial viscosity $(\Delta r)$. At promotion of aggregation model, an increase in the physisorption of isoflurane hydrates on the interface (increase in $\Delta f$ ) promotes an interaction between those physisorbed isoflurane hydrates. That interaction process leads to aggregation of isoflurane hydrates themselves [5] [27] [28] and also suppresses more strongly the interface. This effect would cause a discontinuous and subsequent a slight increase in the interfacial viscosity $(\Delta r)$. The increase in both $\Delta f$ and $\Delta r$ on the higher concentration range ( $\geq 6 \mathrm{mM}$ ) may occur as a synergistic or simultaneous effect of both multi-physisorption and promotion of aggregation. Such physisorption process by isoflurane hydrates on the interface also causes a rapid second saturation state.

\subsubsection{The Interaction between DMPC Monolayer and Isoflurane}

The present DMPC monolayer is an expandability rich monolayer as mentioned in Section 4.1. Therefore, it would be hard to cause the structural change in the monolayer-water interface i.e. no change in $\Delta r$ even if isoflurane hydrate physisorbed on the interface. It can be also explained as a simple physisorption model of isoflurane hydrate to the DMPC monolayer [53]-[55]. On the first saturation range to around $5 \mathrm{mM}$, isoflurane hydrates physisorb on the DMPC monolayer-water interface leads to increase in $\Delta f$ (Figure 3(a)). Further increase in isoflurane concentration leads to an increase in the amount of physisorbed isoflurane hydrate thus more increase in $\Delta f$ was noticed. Due to expandable nature of DMPC-water interface, isoflurane hydrates just physisorb on the interface and do not change the viscosity of the interface. From reaching to a first saturation value of $\Delta f$ $(2.2 \mathrm{~Hz}$ ) at around $5 \mathrm{mM}$ (Figure 3(a)), we roughly estimated the mean molecular mass of isoflurane hydrate from the value of $\Delta f\left(2.2 \mathrm{~Hz}=26.8 \mathrm{ng} / \mathrm{cm}^{2}\right.$ (Sauerbrey's equation)) as worked out by QCM [15] [28] [41]. Molecular area of the isoflurane hydrate was calculated to be $4.5 \mathrm{~nm}^{2} /$ hydrate. Considering the size of isoflurane hydrate, physisorption layer of isoflurane hydrates would be formed on the interface, where isoflurane molecules are not in a dense state and maintain a semi-saturation state, similar to the DPPC monolayer/water interface. Amount of physisorbed isoflurane hydrates to DMPC monolayer-water interface was $26.8 \mathrm{ng} / \mathrm{cm}^{2}$ which is more than that adsorbed to DPPC monolayer $19.5 \mathrm{ng} / \mathrm{cm}^{2}$. Expandability rich DMPC monolayer it is hard to cause change in interfacial property by physisorption of isoflurane hydrate. Due to the high expandability, $\Delta f$ in the DMPC monolayer changes from lower concentration of isoflurane compared to the case of DPPC monolayer and it also corresponds to the approach to the first saturation state at a lower concentration of isoflurane.

On the higher concentration at more than $5 \mathrm{mM}$ (Figure 3), isoflurane hydrates would physisorb still more on the interface. Because of no change in $\operatorname{Dr}$ (viscosity) at this concentration range $(<8 \mathrm{mM})$, the physisorption process can be explained as a simple multi-physisorption or promotion of aggregation model of isoflurane hydrate to the DMPC monolayer [13] [53]-[55]. Continuous physisorption of isoflurane hydrates (increase in Df) leads to multilayering or aggregation of isoflurane hydrates themselves. This process would make further physisorption of hydrates easy. Such physisorption process by isoflurane hydrates on the interface also causes a rapid second saturation state. However, this is quite different from that at DPPC monolayer/water interface which involves the structural change in the interface by the physisorption of isoflurane hydrates. 


\section{Conclusion}

In the present study, the interaction between two phospholipid monolayers DPPC and DMPC on the water surface and anesthetic isoflurane has been investigated using horizontally attached QCM and QCI devices. It was noticed that anesthetic isoflurane hydrate physisorbed on elasticity DPPC monolayer and changed its viscosity. While DMPC monolayer was expandability rich, no change in monolayer viscosity occurred. Process of physisorption showed a two-step change in the range of added isoflurane concentration, indicating that isoflurane aggregation was probably formed on each monolayer-water interface. Isoflurane hydrate physisorbed on the monolayer and brought changes in the monolayer properties. As investigated by several researchers [56] [57], anesthetic action was evaluated due to anesthetic-membrane protein interaction. However, our investigation showed that anesthetic had a possibility of acting on the lipid parts or lipid-body fluid interface and changing those properties. Thus, our reported study indicated that anesthetics acted to not only membrane protein limited but also whole membrane including lipid molecules and proteins.

\section{Acknowledgements}

This work was supported by a Grant-in-Aid from the Ministry of Science, Education, Sports and Culture (No. 15750118, 21750143 and 24550154), DVA Medical Research and Development Funds, and Sakakibara Memorial Hospital Incorporated Foundation.

\section{References}

[1] Singer, S.J. and Nicolson, G.L. (1972) The Fluid Mosaic Model of the Structure of Cell Membranes. Science, 175, 720-731. http://dx.doi.org/10.1126/science.175.4023.720

[2] Simons, K. and Ikonen, E. (1997) Functional Rafts in Cell Membranes. Nature, 387, 569-572. http://dx.doi.org/10.1038/42408

[3] Gennis, R.B. (1990) Biomembrane, Molecular Structure and Function. Springer, New York.

[4] Gellman, S.H. (1997) Molecular Recognition. Chemical Reviews, 97, 1231-1232. http://dx.doi.org/10.1021/cr970328j

[5] Arai, T. (2001) Lectures for Anesthesia and Resuscitation. Kokuseido Co. Ltd., Tokyo.

[6] Yoshimura, N. (2002) Standard Anesthesia Science. Igaku-Shoin Ltd., Tokyo.

[7] Hyodo, M. (2006) Anesthesiology 11 Review. Kinpodo Inc., Kyoto.

[8] Ueda, I. and Yoshida, T. (2002) Interaction of Volatile An-Esthetics with Micellar Systems. In: Encyclopedia of Surface and Colloid Science, Marcel Dekker, Inc., New York.

[9] Matsuki, H. and Ueda, I. (2001) Are There Any Specific Receptors for Anesthetics? Seibutsu Butsuri, 41, 4-8. http://dx.doi.org/10.2142/biophys.41.4

[10] Cherkin, A. and Catchpool, J.F. (1964) Temperature Dependence of Anesthesia in Goldfish. Science, 144, $1460-1462$. http://dx.doi.org/10.1126/science.144.3625.1460

[11] Flook, V., Adey, G.D., Dundas, C.R. and White, D.C. (1974) Effect of Temperature on Potency of Anesthetic Agents. Journal of Applied Physiology, 37, 552-555.

[12] McKenzie, J.D., Calow, P., Clyde, J., Miles, A., Dickinson, R. and Lieb, W.R. (1992) Effect of Temperature on the Anaesthetic Potency of Halothane, Enflurane and Ethanol in Daphnia Magna (Cladocera: Crustacea). Comparative Biochemistry and Physiology Part C: Toxicology \& Pharmacology, 101, 15-19. http://dx.doi.org/10.1016/0742-8413(92)90193-B

[13] Yoshida, T., Okabayashi, H., Kamaya, H. and Ueda, I. (1989) Stable and Unstable Binding of a Volatile Anesthetic Enflurane with Model Lipid Vesicle Membranes. Biochimca et Biophysica Acta, 979, 287-293. http://dx.doi.org/10.1016/0005-2736(89)90246-0

[14] Cantor, R.S. (1997) The Lateral Pressure Profile in Membranes: A Physical Mechanism of General Anesthesia. Biochemistry, 36, 2339-2344. http://dx.doi.org/10.1021/bi9627323

[15] Yamamoto, Y., Shervani, Z., Shimoaki, T., Yokoyama, T., Ando, T., Somekawa, A., Takayama, M., Tamaoki, K., Yoshida, T., Taga, K., Kamaya, H. and Ueda, I. (2010) Physisorption Behavior of Enflurane on the Dipalmitoyl Phosphatidyl Choline (DPPC) Monolayer Using High Sensitive Quartz Crystal Oscillator Method. Colloids and Surfaces A: Physicochemical and Engineering Aspects, 367, 47-51. http://dx.doi.org/10.1016/j.colsurfa.2010.06.015

[16] Sauerbrey, G. (1959) Verwendung von schwingquarzen zur wung dner schichten und zur mikrowung. Zeitschrift fur Physik, 155, 206-222. http://dx.doi.org/10.1007/BF01337937 
[17] Nomura, T. and Minemura, A. (1980) Behavior of a Piezoelectric Quartz Crystal in an Aqueous Solution and the Application to the Determination of Minute Amount of Cyanide. Chemical Society of Japan, 10, 1621-1625.

[18] Bruckenstein, S. and Shay, M. (1985) An in Situ Weighing Study of the Mechanism for the Formation of the Adsorbed Oxygen Monolayer at a Gold Electrode. Journal of Electroanalytical Chemistry, 188, 131-136. http://dx.doi.org/10.1016/S0022-0728(85)80057-7

[19] Aoki, K., Miyamoto, T. and Ohsawa, Y. (1989) The Determination of the Selectivity Coefficient of $\mathrm{Na}^{+}$versus $\mathrm{Li}^{+}$on Prussian Blue Thin Film in Propylene Carbon-Ate by Means of a Quartz Crystal Microbalance. Bulletin of Chemical Society of Japan, 62, 1658-1659. http://dx.doi.org/10.1246/bcsj.62.1658

[20] Ebara, Y. and Okahata, Y. (1994) A Kinetic Study of Concanavalin: A Binding to Glycolipid Monolayers by Using a Quartz Crystal Microbalance. Journal of American Chemical Society, 116, 11209-11212. http://dx.doi.org/10.1021/ja00104a001

[21] Sato, T., Serizawa, T., Ohtake, F., Nakamura, M., Terabayashi, T., Kawanishi, Y. and Okahata, Y. (1998) Quantitative Measurements of the Interaction between Monosialoganglioside Monolayers and Wheat Germ Agglutinin (WGA) by a Quartz Crystal Microbalance. Biochimica et Biophysica Acta, 1380, 82-92. http://dx.doi.org/10.1016/S0304-4165(97)00133-5

[22] Matsuno, H., Furusawa, H. and Okahata, Y. (2005) Kinetic Studies of DNA Cleavage Reactions Catalyzed by an ATPDependent Deoxyribonuclease on a 27-MHz Quartz-Crystal Microbalance. Biochemistry, 44, 2262-2270. http://dx.doi.org/10.1021/bi048486+

[23] Tatsuma, T. and Oyama, N. (1993) Suishoushindousi niyoru kotaihyoumen no kyarakutarizetion to sono DNA kensyutu heno ouyou. Tyouonpa TECHNO, 5, 33-36.

[24] Muramatsu, H. and Kimura, K. (1992) Quartz Crystal Detector for Microrheological Study and Its Application to Phase Transition Phenomena of Langmuir-Blodgett Films. Analytical Chemistry, 64, 2502-2507. http://dx.doi.org/10.1021/ac00045a008

[25] Yuan, Y., Cai, Y., Zie, Q. and Yao, S. (2002) Piezoelectric Quartz Crystal Impedance Study of the Pb ${ }^{2+}$-Induced Precipitation of Bovine Serum Albumin and Its Dissolution with EDTA in an Aqueous Solution. Analytical Science, 18, 767-771. http://dx.doi.org/10.2116/analsci.18.767

[26] Xie, Q., Xiang, C., Zhang, Y., Yuan, Y., Liu, M., Nie, L. and Yao, S. (2002) In Situ Monitoring of Gold-Surface Adsorption and Acidic Denaturation of Human Serum Albumin by an Isolation-Capacitance-Adopted Electrochemical Quartz Crystal Impedance System. Analytica Chimica Acta, 464, 65-77. http://dx.doi.org/10.1016/S0003-2670(02)00487-7

[27] Yamamoto, Y., Taga, K., Yoshida, T., Kamaya, H. and Ueda, I. (2006) Action Mechanism of Water Soluble Ethanol on Phospholipid Monolayers Using a Quartz Crystal Oscillator. Journal of Colloid and Interface Science, 298, 529-534. http://dx.doi.org/10.1016/j.jcis.2005.12.044

[28] Yamamoto, Y., Ando, T., Takayama, M., Egami, T., Ohtsu, Y., Sakurai, A., Yoshida, T., Taga, K., Kamaya, H. and Ueda, I. (2008) Interaction between Phospholipid Mono-Layer and Volatile Anesthetics Using Quartz Crystal Oscillator Methods. Colloids and Surfaces A: Physicochemical and Engineering Aspects, 317, 568-575. http://dx.doi.org/10.1016/j.colsurfa.2007.11.037

[29] Hatta, I. and Murata, M. (2000) Seitaimaku no Dynamics. Kyoritsu Shuppan Co., Ltd., Tokyo.

[30] Yoshida, D., Yokoyama, T., Shimoaki, T., Tomita, T., Yoshida, T., Yamamoto, Y., Taga, K., Sumino, A., Dewa, T., Nango, M., Yamamoto, M. and Shervani, Z. (2013) Morphology Observation of Dipalmitoylphosphatidyl Choline (DPPC) Monolayer on Water Surface by Dropping Method. Journal of Biophysical Chemistry, 4, 114-121. http://dx.doi.org/10.4236/jbpc.2013.44016

[31] Sato, T., Serizawa, T. and Okahata, Y. (1994) Recognition of Monosialoganglioside $\left(\mathrm{GM}_{3}\right)$ Reconstituted in Sphingomyerin and Glucosylceramide Membranes against Wheat Germ Agglutinin: Quantitative Analyses by a Quartz Crystal Microbalance. Biochemical and Biophysical Research Communications, 204, 551-556.

[32] Ebara, Y., Itakura, K. and Okahata, Y. (1996) Kinetic Studies of Molecular Recognition Based on Hydrogen Bonding at the Air-Water Interface by Using a Highly Sensitive Quartz-Crystal Microbalance. Langmuir, 12, 5165-5170. http://dx.doi.org/10.1021/la9603885

[33] Okahata, Y. and Furusawa, H. (2004) Gravimetry of Biomolecules at the Water-Substrate Interface-Quartz-Crystal Microbalance. Journal of Surface Science Society of Japan, 25, 131-138. http://dx.doi.org/10.1380/jsssj.25.131

[34] Ueda, I. and Yoshida, T. (1999) Hydration of Lipid Membranes and the Action Mechanisms of Anesthetics and Alcohols. Chemistry and Physics of Lipids, 101, 65-79. http://dx.doi.org/10.1016/S0009-3084(99)00056-0

[35] Makino, M. and Kamiya, M. (1996) Effects of Local An-Esthetics on the Dynamic Behavior of Phospholipid Thin Film. Langmuir, 12, 4211-4217. http://dx.doi.org/10.1021/la950917p

[36] Matsuura, N., Elliot, D.J., Frulong, D.N. and Grieser, F. (1997) In Situ Measurement of Lead (II) Ion Binding to an 
Arachidic Acid Langmuir Monolayer Using a Quartz Crystal Microbalance. Colloids and Surfaces A: Physicochemical and Engineering Aspects, 126, 189-195. http://dx.doi.org/10.1016/S0927-7757(97)00005-8

[37] Vilallonga, F. (1968) Surface Chemistry of L- $\alpha$-Dipalmitoyl Lecithin at the Air-Water Interface. Biochimica et Biophysica Acta, 163, 290-300. http://dx.doi.org/10.1016/0005-2736(68)90114-4

[38] Ohe, C., Sasaki, T., Noi, M., Goto, Y. and Itoh, K. (2007) Sum Frequency Generation Spectroscopic Study of the Condensation Effect of Cholesterol on a Lipid Monolayer. Analytical and Bioanalytical Chemistry, 388, $73-79$. http://dx.doi.org/10.1007/s00216-006-1030-0

[39] Mingotaud, A.F., Mingotaud, C. and Patterson, L.K. (1993) Handbook of Monolayers Vol. 1 and 2. Academic Press Inc., California.

[40] Yamamoto, M., Yoshida, D., Mori, H., Sekiguchi, K. and Yamamoto, Y. (in preparation) Lower-Density Condensed Langmuir Films of Dipalmitoylphosphatidylcholine Utilizing the Two Hydrocarbon Chains of Each Molecule.

[41] Yamamoto, Y., Shervani, Z., Shimoaki, T., Yoshida, D., Yokoyama, T., Yoshida, T., Taga, K., Kamaya, H. and Ueda, I. (2011) Study of Physisorption of Volatile Anesthetics on Phospholipid Monolayers Using a Highly Sensitive Quartz Crystal Microbalace (HS-QCM). Journal of Biophysical Chemistry, 2, 68-74. http://dx.doi.org/10.4236/jbpc.2011.22010

[42] Nakagaki, M., Tomita, K. and Handa, T. (1985) Interaction of Differently Oriented Lipids in Monolayer: Mixed Monolayers of 16-(9-Anthroyloxy)palmitic Acid with Phosphatidylcholine and Cholesterol. Biochemistry, 24, 4619-4624. http://dx.doi.org/10.1021/bi00338a021

[43] Nagayama, K. (2000) Mizu to Seimei. Kyoritsu Shuppan Co., Ltd., Tokyo.

[44] Seto, N., Mashimo, T., Yoshiya, I. and Taniguchi, Y. (1991) Kyunyumasuiyaku no youkaido-Masuikikoukenkyuu no tameni. Anesthesia and Resuscitation, 27, 321-324.

[45] Bergadano, A., Lauber, R., Zbinden, A., Schatzmann, U. and Moens, Y. (2003) Blood/Gas Partition Coefficients of Halothane, Isoflurane and Sevoflurane in Horse Blood. British Journal of Anaesthesia, 91, 276-278. http://dx.doi.org/10.1093/bja/aeg151

[46] Yamamoto, Y., Taga, K., Yoshida, T., Kamaya, H. and Ueda, I. (2006) Temperature Dependence of Thermodynamic Activity in Volatile Anesthetics: Correlation between Anesthetic Potency and Activity. Journal of Colloid and Interface Science, 301, 488-492. http://dx.doi.org/10.1016/j.jcis.2006.05.030

[47] Yokono, S., Shieh, D.D. and Ueda, I. (1981) Interfacial Preference of Anesthetic Action upon the Phase Transition of Phospholipid Bilayers and Partition Equilibrium of Inhalation Anesthetics between Membrane and Deuterium Oxide. Biochimica et Biophysica Acta, 645, 237-242. http://dx.doi.org/10.1016/0005-2736(81)90194-2

[48] Hauet, N., Artzner, F., Boucher, F., Gabrielle-Madelmont, C., Clouteir, I., Keller, G., Lesieur, P., Durand, D. and Patermostre, M. (2003) Interaction between Artificial Membranes and Enflurane, a General Volatile Anesthetic: DPPCEnflurane Interaction. Biophysical Journal, 84, 3123-3137. http://dx.doi.org/10.1016/S0006-3495(03)70037-X

[49] Yoshida, T., Takahashi, K., Kamaya, H. and Ueda, I. (1988) ${ }^{19}$ F-NMR Study on Micellar Solubilization of a Volatile Anesthetic Halothane: Dose-Related Biphasic Interaction. Journal of Colloid and Interface Science, 124, 177-185. http://dx.doi.org/10.1016/0021-9797(88)90338-4

[50] Yoshida, T., Takahashi, K. and Ueda, I. (1989) Molecular Orientation of Volatile Anesthetics at the Binding Surface: ${ }^{1} \mathrm{H}$ - and ${ }^{19}$ F-NMR Studies of Submolecular Affinity. Biochimica et Biophysica Acta, 985, 331-333. http://dx.doi.org/10.1016/0005-2736(89)90421-5

[51] Yoshino, A., Yoshida, T. and Takahashi, K. (1989) ${ }^{2}$ H NMR Study of the Behaviour of Water in a Reversed Mi-Cellar System: Hydrogen Bond Breaking and Clathrate Formation by an Inhalation Anaesthetic. Magnetic Resonance in Chemistry, 27, 344-347. http://dx.doi.org/10.1002/mrc.1260270409

[52] Gaussion Literature Citation. Frisch, M.J., Trucks, G.W., Schlegel, H.B., Scuseria, G.E., Robb, M.A., Cheeseman, J.R., Scalmani, G., Barone, V., Mennucci, B., Petersson, G.A., Nakatsuji, H., Caricato, M., Li, X., Hratchian, H. P., Izmaylov, A.F., Bloino, J., Zheng, G., Sonnenberg, J.L., Hada, M., Ehara, M., Toyota, K., Fukuda, R., Hasegawa, J., Ishida, M., Nakajima, T., Honda, Y., Kitao, O., Nakai, H., Vreven, T., Montgomery Jr., J.A., Peralta, J.E., Ogliaro, F., Bearpark, M., Heyd, J.J., Brothers, E., Kudin, K.N., Staroverov, V.N., Kobayashi, R., Normand, J., Raghavachari, K., Rendell, A., Burant, J.C., Iyengar, S.S., Tomasi, J., Cossi, M., Rega, N., Millam, N.J., Klene, M., Knox, J.E., Cross, J.B., Bakken, V., Adamo, C., Jaramillo, J., Gomperts, R., Stratmann, R.E., Yazyev, O., Austin, A.J., Cammi, R., Pomelli, C., Ochterski, J.W., Martin, R.L., Morokuma, K., Zakrzewski, V.G., Voth, G.A., Salvador, P., Dannenberg, J.J., Dapprich, S., Daniels, A.D., Farkas, Ö., Foresman, J.B., Ortiz, J.V., Cioslowski, J. and Fox, D.J. (2009) Gaussian 09. Revision D.01, Gaussian, Inc., Wallingford CT.

[53] Tsuboi, K., Seki, K., Ouchi, Y., Fujita, K. and Kajikawa, K. (2003) Formation of Merocyanine Self-Assembled Monolayer and Its Nonlinear Optical Properties Probed by Second-Harmonic Generation and Surface Plasmon Resonance. Japan Journal of Applied Physics, 42, 607-613. http://dx.doi.org/10.1143/JJAP.42.607 
[54] Naraoka, R., Kaise, G., Kajikawa, K., Okawa, H., Ikezawa, H. and Hashimoto, K. (2002) Nonlinear Optical Property of Hemicyanine Self-Assembled Monolayers on Gold and Its Adsorption Kinetics Probed by Optical Second-Harmonic Generation and Surface Plasmon Resonance Spectroscopy. Chemical Physics Letters, 362, 26-30. http://dx.doi.org/10.1016/S0009-2614(02)01041-2

[55] Kondo, S., Abe, I. and Ishikawa T. (2001) Kyuchaku no Kagaku. Maruzen Publishing Co. Ltd., Tokyo.

[56] Mashimo, T., Ogli, K. and Uchida, I. (2005) Basic and Systemic Mechanisms of Anesthesia. Elsevier, Amsterdam.

[57] 8th International Conference on Mechanisms of Anesthesia (MAC 2010); J.J.R. Macleod Auditorium, Toronto, Canada: 2010 . 